\title{
A SIMPLE AND LOW COST TECHNIQUE FOR DETERMINING THE GRANULOMETRY OF UPFLOW ANAEROBIC SLUDGE BLANKET REACTOR SLUDGE
}

\author{
A. Laguna*, A. Ouattara**, R. O. Gonzalez***, \\ O. Baron* $\neq$, G. Famá*, R. El Mamouni†, \\ S. Guiot $\}^{*}$, O. Monroy* and H/Macarie M.t $^{*}$
}

* Depto de Biotecnología, Universidad Autónoma Metropolitana-lztapalapa, Av. Michoacan y La Purisima, Col. Vicentina, 09340 México D. F. A. P. 55 535, Mexico ** Université de Ouagadougou, Départment de Microbiologie et Biochimie, 03 B. P. 7021, Ouagadougou 03, Burkina Faso

*** Depto de Matematicas, Universidad Auónama Metropolitana-Izlapalapa, Av. Michoacan y La Purisima, Col. Vicentina, 09340 México D. F. A. P. 55535 , Mexico † Biotechnology Research Institule, NRCC. 6100 Royalmount Avenue, H4P 2R2, Montréal (Québec). Canada

$\$$ Institut de Recherche pour le Développement (IRD. ex-ORSTOM).Ciceron 609.Col. Los Morales, IIS30 México D. F.. Mexico

\section{ABSTRACT}

Four techniques (microscope sizing, calculation from setiling velocities, image and laser analysis) are available nowadays for determining the particle size distribution of upflow anaerobic sludge blanket (UASB) reactor sludge. These techniques present however the disadvantage of being either tedious, imprecise or expensive and hardly applicable in full scale treatment plants. There was then the need for a simple and low cost technique. In this study, a granulometry procedure based on manual humid sieving was evaluated. It was shown that no solid loss occured during the screening and that the particle size profiles were reproducible when performed with sludge samples of $5,10,25$ and $150 \mathrm{ml}$, but not $1 \mathrm{ml}$. Only the results between 10 and $25 \mathrm{ml}$ were however fully identical. It was shown also that the sieving could be performed on sludge samples stored for as long as 50 days at refrigerator temperature and that tap water could be use for the wash and backwash operations without any impact on the particle size profile. The granulometry obtained by image analysis was not comparable to that given by sieving. Nevertheless, no evidence of granule erosion could be found. In any case, the technique allowed us to follow the evolution of sludge granulometry perfectly over time. As a consequence. the manual humid sieving appears to be an adequate technique for determining the granule size distribution of UASB sludges. (c) 1999 Published by Elsevier Science Lid on behalf of the IAWQ. All rights reserved.

\section{KEYWORDS}

Anaerobic reactor; granular sludge; image analysis; particle size distribution; sieving; UASB.

Fonds Documentaire ORSTOM Cote:B*20388 Ex: 1 


\section{INTRODUCTION}

Among all the different types of anaerobic digesters applied at full scale, UASB (Upflow Anaerobic Sludge Blanket) reactors present the best commercial acceptance. The success of these reactors is related to their capacity for biomass accumulation by settling without the need of a carrier. Good settling properties are obtained through the flocculation of the biomass in the form of dense granules with diameters up to several millimetres. Actually, as individual cells and granules have similar densities, the greater settling velocity of the latter is only related to its larger particle size. The study of this phenomenon has lead to the development of several techniques for characterizing the resistance of the granules, their porosity, settling properties; bacterial composition and organization, activity, nature and composition of exopolymers, as well as their size distribution. This last parameter is particularly useful for studying the physico-chemical factors promoting sludge granulation.

To date, four techniques are routinely used to determine the particle size distribution of UASB sludge. Two of them consist in the direct size measurement with a microscope of at least 100 sludge granules immobilized in a petri dish. This can be done either manually with a porton graticule or automatically using image analysis and computerized data processing (Hulshoff Pol, 1989; Dudley et al., 1993). The third method is indirect and consists in determining the settling velocities of a sludge sample and extrapolating the corresponding diameters using equations such as Stokes' law (Hulshoff Pol, 1989; Grotenhuis et al., 1991). The last method involves particle size analysis by laser and has been introduced only recently (Yan and Tay, 1997). Unfortunately all these procedures present several disadvantages. The graticule one is very tedious while the image and laser analysis are expensive (at least $\$ U S 10000$ for image analysis and between 30000 and 60000 for the laser one) and the settling velocity procedure assumes that some correlations between size and velocity are correct which may not be always the case. This last procedure is also poorly sensible and presents a low degree of precision (Grotenhuis et al., 1991). Finally, none of the previous techniques, because of their complexity or cost can be easily set up in treatment plants and as a consequence are almost confined to laboratory studies.

There is then the need for a low cost and simple granulometry technique which could be applied both at lab and full scale. A humid sieving could be such a method since it only requires a set of sieves which cost a few hundred dollars, a furnace and a centrifuge or a filtering device always available in laboratories realizing water analysis. Such sieving has been used before for that purpose by several researchers (Tur and Huang, 1997; Yoda and Nishimura, 1997), nevertheless its validity has never been assessed. For instance, based on some studies with digested sludge and automatic sieving (Leschber and Haacke, 1975), it is believed that this method causes granule erosion and yields erroneous measurements (Hulshoff Pol, 1989).

This paper presents the evaluation of a manual granular sludge sieving procedure. The points investigated are (1) the suspended solids recovery after sieving compared to the initial amount present in the sample, (2) the reproducibility of the technique for each sludge volume tested, (3) the range of sample volumes for which the technique gives comparable results, (4) the possibility of using tap water instead of phosphate buffer for granule washing, and (5) the effect of sludge storage at two temperatures on granulometry. The results are also compared to those obtained with image analysis in order to assess if erosion takes place during the sieving.

\section{MATERIALS AND METHODS}

\section{Source of granular sludge}

The sludge used for the study came from a $2400 \mathrm{~m}^{3}$ UASB reactor treating the wastewater of "Central de Malta", a malt factory belonging to the "Cerveceria Cuauhtémoc Moctezuma" Mexican brewery group. This sludge was chosen because it is a good example of granular biomass. It was sampled at two different dates separated by 3 months. The effect of storage on granulometry was evaluated on the second sample and all the other factors on the first one as well as the image analysis. 
The screening was performed with five stainless steel sieves of 8 " diameter having respective mesh openings of $2,0.925,0.76,0.59$ and $0.23 \mathrm{~mm}$ which allowed us to cover the usual granule size range. The sieves were mounted vertically one on the top of the other in increasing order of mesh opening (from bottom to top). A plate of the same diameter was located at the bottom to recover the particles smaller than $0.23 \mathrm{~mm}$. Before analysis, the sludge was vigorously homogenized by hand shaking its storage container several times, and then transferred in a beaker of 2 litres where it was quickly sampled. Depending on the sludge volume tested, sampling was made either with calibrated spoons $(25,150 \mathrm{ml})$ or pipettes $(1,5,10 \mathrm{ml})$. In that last case, the pipette tip was broken in order to have a mouth of around $5 \mathrm{~mm}$ which is at least twice the size of the biggest granules. The spoons had a larger diameter ( $4 \mathrm{~cm}$ for the $25 \mathrm{ml}$ one, $8.6 \mathrm{~cm}$ for the $150 \mathrm{ml}$ one), so that the ratio of spoon to granule diameter was very high. The sample was afterwards deposited on the $2 \mathrm{~mm}$ mesh opening sieve and washed with phosphate buffer $\left(\mathrm{KH}_{2} \mathrm{PO}_{4} 4 \mathrm{~g} / \mathrm{l}, \mathrm{Na}_{2} \mathrm{HPO}_{4} .7 \mathrm{H}_{2} \mathrm{O} 5.09 \mathrm{~g} / \mathrm{l}\right.$, $\mathrm{K}_{2} \mathrm{HPO}_{4} 1.08 \mathrm{~g} / \mathrm{l}, \mathrm{pH}$ 7.3) or tap water to allow the particles less than $2 \mathrm{~mm}$, to separate from the others and flow to the following sieve. The same washing operation was done successively for each sieve until reaching the last one. The granules retained on the different screens were recovered by a backwash using the same solvent. Each fraction was collected in a different beaker and was later centrifuged at $5000 \mathrm{rpm}$ for $15 \mathrm{~min}$ in order to obtain the solids and determine their TSS and VSS. Once the amount of TSS and VSS retained on each sieve was determined, it was possible to calculate by simple addition of these data, the total amount of solids screened and then to determine for each class of size $(<0: 23,[0.23-0.59],[0.59-0.76],[0.76-0.925]$, $[0.925-2],>2 \mathrm{~mm}$ ) the percentage of the total weight that they represent.

\section{Image analysis}

The first step in the image analysis consists of screening a sludge sample of $1 \mathrm{ml}$ through a sieve of 0.149 $\mathrm{mm}$ in order to eliminate the small particles which cannot be detected by the system. The TSS of the sieved portion $\left(\mathrm{M}_{0.149}\right)$ are measured in parallel to the TSS of an unscreened $1 \mathrm{ml}$ sample $\left(\mathrm{M}_{\mathrm{t}}\right)$. Thereafter, an aliquot of the granules retained on the sieve is placed in a petri dish (with a diameter of $3.5 \mathrm{~cm}$ ) followed by the addition of enough phosphate buffer (an equimolar solution of sodium and potassium phosphate, $0.1 \mathrm{M}$ ) to cover them. The petri dish is then observed with a stereomicroscope (WILD, Heerbrugg, Switzerland) equipped with a video camara coupled to a Quantimet Q520 Image Analysis System (Cambridge Instruments Ltd, Cambridge, UK) which automaticaly determines the equivalent diameter of each granule. This value corresponds to the diameter of a sphere with a surface identical to that of the particles. The image analysis gives therefore, a distribution of diameter (D) by number of granules. In order to compare it with the results obtained by sieving, this distribution must be converted to a distribution of diameter by weight Assuming that all granules have equal densities, mass $(M)$ and volume (V) distributions are equivalent since $\mathrm{M}=\mathrm{V} *$ density. The granules being assimilated to spheres, their volumes can be easily assessed $(\mathrm{V}=1 / 6 \Pi$ $\mathrm{D}^{3}$ ). The procedure consists afterwards, (1) to classify the granules by increasing diameter, (2) to group them into classes of size corresponding to the sieving $(<0.23,[0.23-0.59],[0.59-0.76],[0.76-0.925],[0.925-2],>$ $2 \mathrm{~mm}$ ), (3) to calculate for each class the volume that represents all the granules that they contain ( $=$ sum of granule individual volumes) and finally (4) to determine in percentage the fraction that every class represents with respect to the total volume $\left(V_{t}\right)$ of the granules found in the sample $\left(V_{t}=\right.$ sum of individual volumes (vi) of all granules detected by image analysis + volume of particles inferior to $0.149 \mathrm{~mm}=\Sigma$ vi $/$ $\left.\left[\mathrm{M}_{0.149} / \mathrm{M}_{\mathrm{l}}\right]\right)$.

\section{Statistical analysis and suspended solids (SS)}

All the statistical analyses (Anova, Kolmogorov-Smirnov, Student $t$ test, etc) of the data have been performed with the software SPSS version 7.5 for windows (SPSS Inc., Chicago, $\mathrm{L}$, USA). The sludge TSS (Total SS) and VSS (Volatile SS) were determined respectively after drying at $105^{\circ} \mathrm{C}$ for $24 \mathrm{~h}$ and combustion during $\mathrm{I} \mathrm{h}$ at $550^{\circ} \mathrm{C}$ of the dried solids following the procedure described in Standard Methods . (1992). Before analysis, the suspended solids were obtained from the samples by centrifugation as indicated above. 


\section{RESULTS AND DISCUSSION}

Except when mentioned differently, all screening experiments were performed using phosphate buffer as solvent.

\section{Suspended solids recovery}

To. be valid, as first criterion, a granulometry technique must be able to take into account all the suspended particles present in a sample without any loss. It was therefore important to check if the total mass of solids recovered after screening was identical to that of the original unscreened sludge. For that purpose, the TSS and VSS of 10 sludge samples of $25 \mathrm{ml}$ were deternined directly, while 10 other $25 \mathrm{ml}$-samples were submitted to screening and the sum of the TSS and VSS retained on the different sieves was calculated for each of them. As can be seen on Figure 1A, the direct measurements gave TSS and VSS values much more regular than those obtained after sieving. For TSS, the averages were however very similar, 73.7 (SD 7.12) and $74.08^{\circ} \mathrm{g} / \mathrm{l}(\mathrm{SD}=1.08)$ with and without screening, respectively. The difference was somewhat more important for VSS (mean of $57.84 \mathrm{~g} / \mathrm{l}$ with a SD of 0.75 without sieving against $53.75 \mathrm{~g} / \mathrm{l}$ and $\mathrm{SD}$ of 5.21 after sieving). A variance analysis which compared the means for the TSS and VSS with and without screening confirmed that no significant difference existed for the TSS values but that a significant difference (at a $2.5 \%$ level) existed for the VSS. No explanation could be found for this variation, except maybe, that the test should have been performed on a higher number of samples. Because of this result, for the rest of the evaluation only TSS were considered.
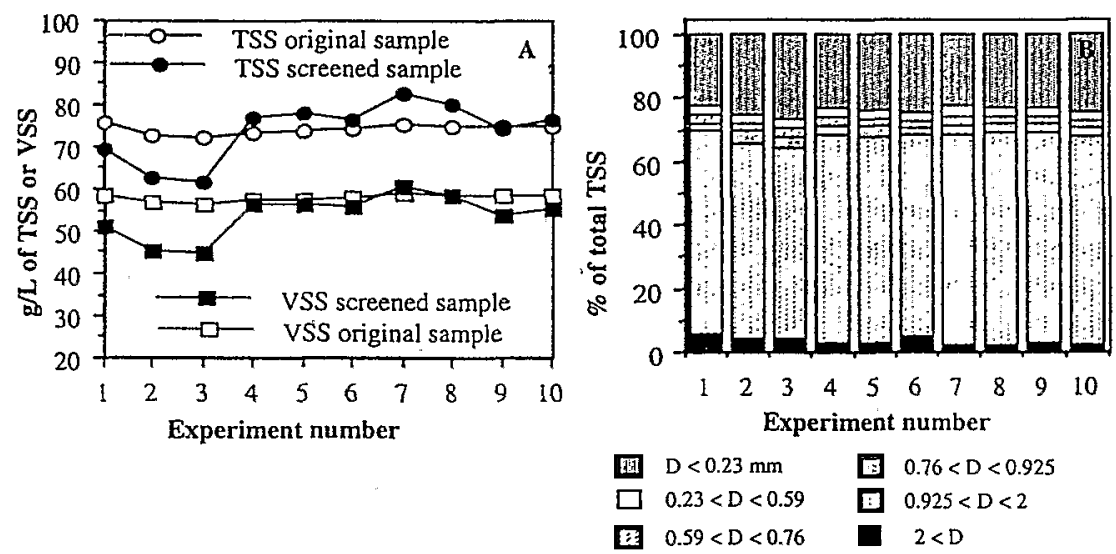

Figure 1. Values of the TSS and VSS obtained for ten sieved and unsieved sludge samples (A) and reproducibility of sieving for each class of size using a sludge volume of $25 \mathrm{ml}(\mathrm{B})$.

\section{$\underline{\text { Reproducibility }}$}

Another important criterion that must cover a granulometry technique is reproducibility. In a first step, this one was tested again on 10 screening using a sludge sample of $25 \mathrm{ml}$. The results (Figure $1 \mathrm{~B}$ ) were analyzed in order to test that the \%TSS obtained for each class of granule size followed a uniform distribution. The data were hence submitted to a Kolmogorov-Smimov test which confirmed that for none of the classes could the uniform distribution hypothesis be rejected. Such uniform distribution indicated that the results obtained for the different sieving are similar and that as a consequence the method is reproducible. Later the same analysis was performed for sludge samples of $1,5,10$ and $150 \mathrm{ml}$. For all of them, except $1 \mathrm{ml}$, the reproducibility was also confirmed (data not shown).

\section{Effect of sludge volume}

Sludge sampling is not at all a problem for full-scale reactors due to their huge volumes. Actually, various litre samples can be taken several times without any consequence on their performance. Unfortunately, this is not the case at lab scale where the total amount of sludge is usually limited to a few hundred millilitres. It 
was then important to know if the volume of sample to be screened could be reduced to less than $25 \mathrm{ml}$ without affecting the results of size distribution. As a consequence, a series of screenings in triplicate were performed with $1,5,10,25$ and $150 \mathrm{ml}$ of sludge. This last value was included in order to see also the impact of using large volumes.

It appeared immediately from the results (Table 1, for clarity only mean values are given) that the screening of $1 \mathrm{ml}$ of sludge gave a size distribution pattern completely different from the others. The fraction with a diameter higher than $2 \mathrm{~mm}$ disappeared while the fraction with a size between 0.925 and $2 \mathrm{~mm}$ was almost reduced by two. The rest of the fractions increased with respect to the other volumes. Such a result is probably related to the fact that it is difficult for a $1 \mathrm{ml}$ sample to be representative of the sludge. As shown by Pereboom (1994), usually in UASB sludge, the number of granules found in each class of size decreases with the increase of diameter. The number of small granules in the sludge, is then, always higher than the number of big ones. Since big granules have the weight of several small granules, their impact on mass is - important even if their number is low. In case the granules bigger than $2 \mathrm{~mm}$ are only present at the density of 5 granules for each $25 \mathrm{ml}$ of sludge, the probability to pick one in $1 \mathrm{ml}$ is low. This will also affect the reproducibility, since the mass particle size distribution of such $1 \mathrm{ml}$ samples will be highly different depending on the presence or absence of a big granule. The same argument can be used to explain the decrease of the [0.925-2] $\mathrm{mm}$ fraction and the increase of the small ones.

Table 1. Mean \%TSS obtained for each class of granule size using different siudge sample volumes, phosphate buffer or water as solvent and image analysis instead of screening

\begin{tabular}{ccccccc}
\hline $\begin{array}{c}\text { Sample } \\
\text { volume } \\
\text { ml }\end{array}$ & $>2$ & {$[0.925-2]$} & $\begin{array}{c}\text { Granule size (mm) } \\
{[0.76-0.925]} \\
\text { \% TSS }\end{array}$ & {$[0.59-0.76]$} & {$[0.23-0.59]$} & $<0.23$ \\
\hline $\begin{array}{c}\text { Sieving } \\
\text { Phosphate buffer } \\
1\end{array}$ & 0 & 36.02 & 4.5 & 14.07 & 15.06 & 30.36 \\
5 & 1.46 & 63.07 & 2.91 & 4.34 & 5.13 & 22.49 \\
10 & 1.56 & 64.23 & 2.82 & 2.49 & 3.33 & 25.56 \\
25 & 1.96 & 67.85 & $2.6 \mathrm{I}$ & 2.12 & 2.88 & 22.55 \\
150 & 0.85 & 70.72 & 1.71 & 1.57 & 4.58 & 20.56 \\
$\begin{array}{c}\text { Tap water } \\
25\end{array}$ & 0.98 & 71.18 & 2.28 & 1.81 & 2.57 & 21.17 \\
Image analysis & & & & & & \\
1
\end{tabular}

For the other volume tested, on first approach, the size distribution looked like much more similar. For each class of granule size, the mean \%TSS obtained at the distinct volumes were compared by a variance analysis. Later, with a multiple Tukey comparison, the means differing by more than $10 \%$ were identified (a $10 \%$ difference is tolerable for this type of analysis). No differences could be found between 10 and $25 \mathrm{ml}$, but some differences appeared between 5 and $150 \mathrm{ml}$ and between them and the other volumes. For the 150 $\mathrm{ml}$ sample, one of the uncomparable values corresponded to the \%TSS of the granules included in the [0.925-2] and < 0.23 classes. In that case, the difference may be related to the fact that despite using more phosphate buffer for washing the granules when screening $150 \mathrm{ml}$ (1600 ml against 700 for $25 \mathrm{ml}$ of sample, 300 for 10 and 150 for $5 \mathrm{ml}$ ), the ratio of buffer volume to sample volume was only 10 compared to $28-30$ $\mathrm{m} / \mathrm{ml}$ in the other cases. This implies that the washing efficiency was probably lower and that as a consequence some small granules could not be separated from the big one in the [0.925-2] class and stayed on the $0.925 \mathrm{~mm}$ sieve. Concordingly the \%TSS of the granules smaller than $0.23 \mathrm{~mm}$ decreased.

\section{Phosphate buffer versus tap water as washing agent}

Phosphate buffer was used at the beginning of the evaluation for the washing and backwash operations in order to provide to the granules an adequate environment in terms of $\mathrm{pH}$ and osmotic pressure. It was actually important to avoid any damage to the celis which could result in granule disruption. The preparatior 
of phosphate buffer being time consuming and having a cost related to the chemicals, it was interesting to test the possibility of replacing it by tap water. With this objective, three sievings with phosphate buffer and three others with tap water were performed on sludge samples of $25 \mathrm{ml}$ (Table 1). For each class of size, as previously, using a variance analysis and a Tukey test for multiple comparison, it was tested if the differences between the mean \%TSS resulting from the use of the two solutions were not higher than $10 \%$. Actually, no difference was found. This result is in accordance with those of Leschber and Haacke (1975) who also observed no differences between the particle size distribution of sewage sludge screened in presence of distilled or tap water. This absence of difference seems to indicate that the $\mathrm{pH}$ and ionic strength of tap water are adequate for that purpose or that the size of the granules is sufficient to make them not affected by osmotic stress during the time of the sieving operation.

Impact of sludge storage on granulometry

Analysis may not be always performed at the time of sampling, particularly when facilities are not available on site and the samples must be sent to another place. It is then important to know how long a sample can be stored without affecting the characteristics to be measured. Storage also allows us to better organize the working schedule since several samples taken at different times can be processed at the same moment. In order to determine this parameter, two identical volumes of sludges sampled on the same day were stored for 50 days, one in a refrigerator and the other at ambient temperature. Every 2 weeks, the granulometry of both sludges was determined by duplicate using a sample volume of $25 \mathrm{ml}$.

At refrigerator temperature, the curves of \%TSS versus time (Figure 2) which could be drawn for each class of size were horizontal lines (slopes of zero). This means that at this temperature the \%TSS did not change significantly with time, indicating therefore, that the sludge can be stored for 50 days in such conditions without any effect on its particle size distribution. At ambient temperature, the situation was different since for the [0.76-0.925] and $>2 \mathrm{~mm}$ classes of granule size, the slopes of the lines drawn were significantly different to zero. Statistical analysis of the data were performed using simple linear regression and the t-test for the time coefficient. It must be noted that by the time of performing the analysis, the ambient temperature increased above $30^{\circ} \mathrm{C}$. As a consequence, the different comportment observed at the low temperatures could be the result of different metabolic activities. Decay rate (cell lysis) in starving conditions is actually more important at higher than lower temperature (Wu et al., 1995) which could probably explain the reduction of size which was observed.

\section{Image analysis}

The image analysis involving only one screening in order to remove the undetectable small particles, the granules are supposed to be submitted to much less shear stress than during screening on multiple sieves and to keep their size integrity better. As a consequence, image analysis was supposed to allow the detection of any damage caused to granules by erosion during the sieving procedure. Image analysis was therefore performed on 12 samples of the sludge used for the screening evaluation. The size distribution obtained (Table 1) appeared to be very different to those resulting from the sieving of the various sludge volumes even when using $1 \mathrm{ml}$. For instance, with image analysis, the granules bigger than $2 \mathrm{~mm}$ represented more than $15 \%$ of the total TSS against less than $2 \%$ for screening. The variations observed cannot be explained however by granule erosion since the $2 \mathrm{~mm}$ sieve is the first to be in contact with the sludge and its mesh opening is too high to cause an important shear stress during granule flowing. In fact the difference seems due to the point that the diameter given by image analysis are calculated assuming that granules are spherical. Central de Malta's sludge contained unfortunately a certain amount of thin granules with a fusoid form. The surface of such particles may correspond to that of a sphere with a diameter higher than $2 \mathrm{~mm}$, but their narrow width compared to their length could permit them to cross the $2 \mathrm{~mm}$ sieve in vertical position. This would result for image analysis in an artificial increase of the \%TSS corresponding to the big granules and for the screening procedure to decrease this fraction without any correlation with crosion. 

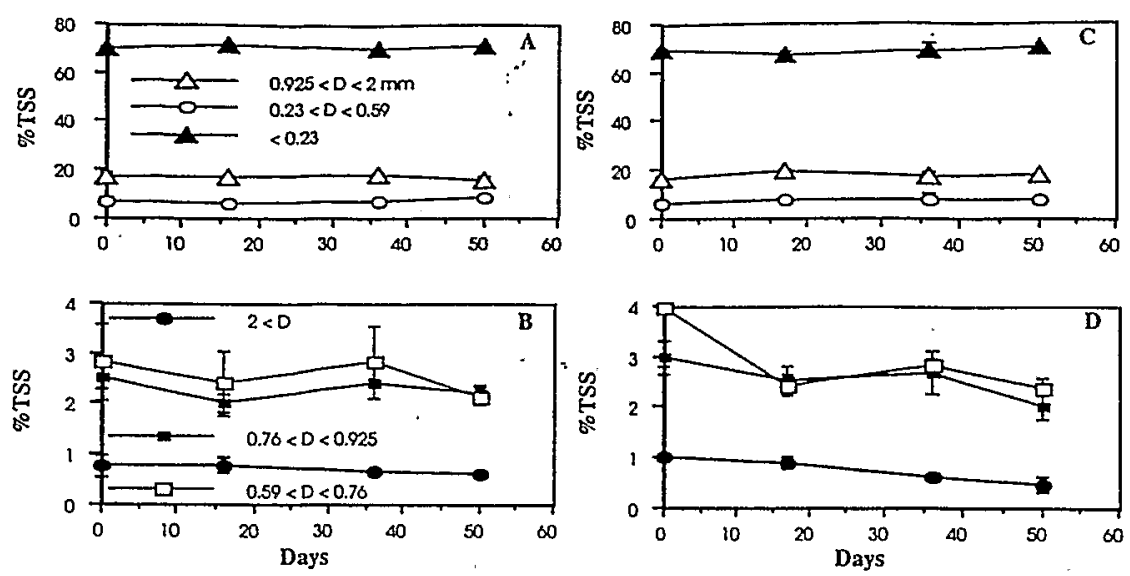

Figure 2. Evolution of sludge granulometry kept in a refrigerator $(A, B)$ or ambient temperature (C, D) (bars represent standard deviation, when not visible they have the size of the symbols).

\section{Practical application of the technique}

The sieving procedure with $25 \mathrm{ml}$-samples and phosphate buffer as washing agent was used to follow during 54 days the granulometry of a 21 UASB reactor sludge operated on cheese wastewater with an upflow velocity of $0.5 \mathrm{~m} / \mathrm{h}$, but also to determine the granulometry of various samples of Central de Malta's (CM) $2400 \mathrm{~m}^{3}$ reactor sludge collected at different dates between 1995 and 1998. As can be seen in Figure 3A, for the lab scale reactor, the sieving technique permitted perfectly to visualize (1) a segregation of the sludge bed, the biggest granules being more abundant at the bottom and the smallest at the top, and (2) an increase of the fraction corresponding to the biggest granules with time, both at the bottom and top of the sludge bed. In the same manner, the evolution of Central de. Malta's sludge could be followed (Figure 3B).

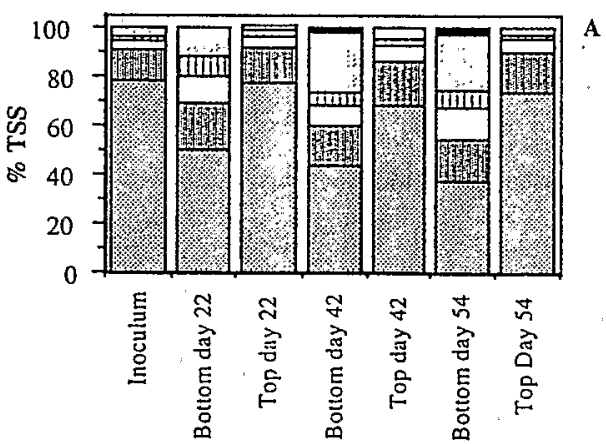

$\begin{array}{ll}2<\mathrm{D} \\ \text { [1] } & 0.925<\mathrm{D}<2 \\ 0.76<\mathrm{D}<0.925\end{array}$

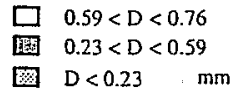

A

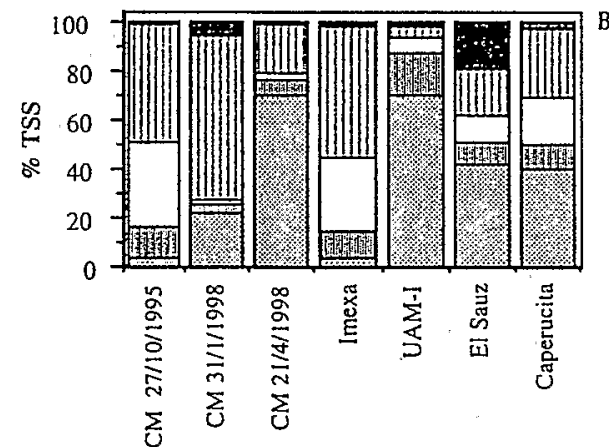

Figure 3. Evolution of the sludge bed granulometry of a lab scale UASB reactor fed with cheese wastewater (A) and comparison of the granulometry of sludges from different full scale digesters (B).

Using the same procedure $(25 \mathrm{ml}$ sample, phosphate buffer), the technique was finally applied to characterize the sludge granulometry of two full scale UASB reactors of 50 and $500 \mathrm{~m}^{3}$ treating respectively domestic sewage (UAM-I) and yeast wastewater (Imexa), but also to a UASB reactor of $80 \mathrm{~m}^{3}$ (Caperucita) and an anaerobic lagoon of $4000 \mathrm{~m}^{3}$ (EI Sauz) both treating cheese wastewater. The results obtained (Figure $3 \mathrm{~B}$ ) demonstrate equally that the sieving technique is valuable to compare the granulometry of sludges from different sources. 
- The sieving technique can be used to determine the granulometry of UASB reactor sludges. All screening performed with $5,10,25$ and $150 \mathrm{ml}$ will give reproducible results while only screening performed in the range of 10-25 $\mathrm{ml}$ will give identical values. In order to compare the screening done by different laboratories, this range of volume should be prefered. Tap water can be used for the washing and backwash operations since it yields identical results with phosphate buffer. The sludge can be stored up to 50 days in a refrigerator without any impact on its particle size distribution. Since screening and image analysis gave uncomparable distributions, the possibility of sludge erosion could not be discarded, but this is of little importance because the technique allows us to observe the evolution of the sludge particle size profile over time. The main disadvantage of the technique is that it does not give any information on the number of granules and that as a consequence, a mean diameter cannot be determined unless similar intervals of mesh opening between sieves are used. However, an advantage of the technique is that it can be performed in series with SVI determinations. Three parameters (SVI, granulometry and TSS concentration) can, hence, be obtained with only one sludge sample. Finally, it should be mentioned that the sludge granulometry can be known with greater precision, simply by increasing the number of sieves. Sieving with automatic shakers is not advised unless no impact on granule size integrity can be demonstrated. Such apparatus would require nevertheless probably higher sample volumes.

\section{ACKNOWLEDGEMENTS}

Aboubakar Ouattara was financially supported by IRD and the Mexican National Council for Science and Technology (Conacyt). All the companies cited in Fig. 3B are thanked for having facilitated the sampling of the sludge of their respective anaerobic treatment plants. We thank also Dr. Alberto Castillo for his fine suggestions in statistical analysis.

\section{REFERENCES}

APHA, AWWA, WPCF. (1992). Standard Methods for the Examination of Water and Wastewater, 18th edition, Washington D. C.

Dudley, B. T., Howgrave-Graham, A. R., Bruton, A. G. and Wallis, F. M. (1993). Image analysis to quantify and measure UASB digester granules. Biotechnol. Bioeng., 42, 279-283.

Grotenhuis, J. T. C., Kissel, J. C., Plugge, C. M., Stams, A. J. M. and Zehnder, A. J. B. (1991). Role of substrate concentration in particle size distribution of methanogenic granular sludge in UASB reactors. Wot. Res., 25(1), $21-27$.

Hulshoff Pol., L. W. (1989). The phenomenon of granulation of anaerobic sludge. PhD thesis, Agricultural University of Wageningen, The Netherlands, 120 pages.

Leschber, R. and Haacke, W. (1975). Sewage sludge research with special emphasis in the particle size distribution. Vom Wasser, 45, 305-325 (in German).

Pereboom, J. H. F. (1994). Size Distribution model for methanogenic granules from full scale UASB and IC reactors. Wat. Sci. Tech, 30(12), 211-221.

Tur, M. Y. and Huang. J. C. (1997). Treatment of phthalic waste by anaerobic hybrid reactor. J. Environ. Eng., 123(11), 10931099.

Wu, W. M., Jain, M. K., Thiele, J. H. and Zeikus, J. G. (1995). Effect of storage on the performance of methanogenic granules. Wat. Res., 29(6), 1445-1452.

Yan, Y. G. and Tay, I. H. (1997). Characterization of the granulation process during UASB start-up. Wat. Res., 31( $/), 1573-1580$.

Yoda, M. and Nishimura, S. (1997). Controlling granular sludge floatation in UASB reactors. Wat. Sci. Tech., 36(6/7), 165-173. 